\title{
Short Communication PHYSIOLOGICAL CHANGES AND SHELF LIFE OF MANGO (Mangifera indica L.) INFLUENCED BY POST HARVEST TREATMENTS
}

\author{
M.I. Hoque ${ }^{1^{*}}$, S. Chowhan ${ }^{1}$, and M. Kamruzzaman ${ }^{2}$ \\ ${ }^{1}$ Adaptive Research and Extension Division, Bangladesh Institute of Nuclear Agriculture \\ Mymensingh-2202, Bangladesh \\ ${ }^{2}$ Plant Breeding Division, Bangladesh Institute of Nuclear Agriculture, Mymensingh-2202, Bangladesh
}

\begin{abstract}
The experiment examined the efficacy of various post harvest treatments namely control, hot water treatment, thin plastic film, chlorinated water, neem extract and garlic extract on shelf life and quality of mango. Parameters studied were colour, firmness, disease severity, disease incidence, total soluble solids, total weight loss, moisture content, dry matter and shelf life of mango. The longest shelf life of 15.41 days was found in mango fruits wrapped with thin plastic film.
\end{abstract}

Keywords: Self life, postharvest, physiological change, mango, treatment

\section{INTRODUCTION}

Mango is one of the most extensively exploited fruits for food, juice, flavor, fragrance and color, making it a common ingredient in new functional foods often called super fruits (Cole, 1984; Bayarri et al., 2001). The fruit is very popular with the masses due to its wide range of adaptability, high nutritive value, and richness in variety, delicious taste and excellent flavour. A climacteric fruit, the mango ripens quickly after harvest (between 3 and 9 days) (Mitra and Baldwin, 1997). This short period seriously restricts long distance marketing. Apart from that sensitivity to disease and high temperature, and perishability due to faster ripening or softening of the fruit, limit its potential in terms of storage, packaging and transport (Mitra and Baldwin, 1997). Proper postharvest treatments and packaging are required for maintaining better quality, extended shelf life and having access to international markets (Anwar and Malik, 2007). Shelf life of fruits could be extended by precooling, chemical treatments, low temperature, different botanical extracts, and so on. However, ventilated low-density polyethylene (LDPE) have also been found to be beneficial, as this material maintains humidity, which results in less shrinkage during

*Corresponding author e-mail: apu.pstu@gmail.comm 
storage (Tharanathan et al., 2006). Different botanical extracts viz. neem and garlic, and coating like sesame oil influence the shelf life and maintain quality of mango (Rodov et al., 1997). The combination of modified atmospheric packaging (MAP) with effective decay control measures can extend the postharvest life of mango fruit (Rodov et al., 1997). Now-a-days very few fruitful techniques are available in Bangladesh to prolong shelf life of mango. Hence, it is necessary to develop more effective techniques to reduce the postharvest losses for prolonging economic storage life of mango. However, reports on postharvest management practices, especially with regards to mango are very inadequate in scientific literature. At the same time very, little systematic study so has been conducted in Bangladesh to reduce the postharvest losses and extension of shelf life of mango.

\section{MATERIALS AND METHODS}

The present experiment was conducted at the laboratory of the Bangladesh Institute of Nuclear Agriculture, Mymensingh, in July 2015. The temperature and relative humidity of the storage room were recorded daily during the study period with a digital thermo hygrometer (THERMO, TFA, and Germany). The minimum and maximum temperatures during the study period of the storage room were 25.2 to $31.3^{\circ} \mathrm{C}$, respectively. The materials used for the experiment were the freshly harvested mango fruits of cv. Fazli. The fruits were collected from local grower of Chapinawabganj. The fruits at the commercial maturity with uniform size, shape, and free of any visible defects, disease symptoms and insect infestations were harvested and transported to the laboratory of the Bangladesh Institute of Nuclear Agriculture, Mymensingh, with careful handling to avoid damage and injury. The experiment consisted of six treatments such as: $\mathrm{T}_{0}$ : Control (mango fruit were not subjected to treatments), $\mathrm{T}_{1}$ : hot water treatment $\left(50^{\circ} \mathrm{C}\right.$ for $\left.5 \mathrm{~min}\right), \mathrm{T}_{2}$ : Thin $(20$ microns $)$ plastic film, $\mathrm{T}_{3}$ : chlorinated water (two pieces of chlorine tablets were mixed with 1 litre of distilled water), $\mathrm{T}_{4}$ : neem extract (500 g neem leaves $/ 500 \mathrm{~L}$ water), $\mathrm{T}_{5}$ : Garlic extract (500 g garlic cloves $/ 5001$ water). The experiment was laid out in a completely randomized design (CRD) with three replications of six fruits in each replication.

\section{RESULTS AND DISCUSSION}

It was observed that color changes of mango depend on various postharvest treatments. The postharvest treatments showed significant variation in respect of peel color change of mangoes. The changes in colour of mango were determined using a numerical rating scale of $1-7$, where $1=$ green, $2=$ breaker, $3=$ up to $25 \%$ yellow, 4 $=25-<50 \%$ yellow, $5=50-<75 \%$ yellow, $6=75-100 \%$ yellow and $7=$ blackened. Similar method was followed by Hassan (2006). At the $11^{\text {th }}$ day of storage, the scores of peels color was the order of 6.92 (Control) $>6.83$ (chlorinated water) $>5.61$ (hot water treatment) $>4.67$ (garlic extract) $>4.08$ (neem extract) $>3.83$ (thin plastic film). Later at 15 days after storage, peel color of 5.75 was obtained only at thin plastic film. The peel color scores increased as the duration of storage progressed at ambient 
temperature. The increase in color score during storage might be due to series of physico-chemical changes like the breakdown of chlorophyll and increase in carotenoid pigments of the pulp caused by enzymatic oxidation and photo degradation.

The faster rate of color change of mango under control treatment may be due to the rapid activity of some enzymes that are responsible for the color changes of mango Robinson (1996). The delay in ripening and senescence of mango fruits in the thin plastic film may be attributed to the inhibition of different chemical changes like chlorophyll breakdown. The result of the present study is also supported by the findings of Robinson (1996). He stated that during color changes, the pulp of the fruit became softer and sweeter as the ratio of sugars to starch increased and the characteristics aroma was produced. These findings were at per with DoreyappaGowda and Huddar (2001) who reported that the green peel color of mature Alphonso and other varieties of mango turned from light green or green or dark green to light yellow or yellow or orange yellow due to the breakdown of chlorophyll due to a series of physico-chemical changes during ripening, leading to disappearance of green color.

Firmness of mango was determined by hand feeling using a numerical rating scale of 1-6 where, $1=$ mature hard, $2=$ sprung, $3=$ between sprung and eating ripe, $4=$ eating ripe, $5=$ over ripened $6=$ totally unfit for consumption. Similar method was mentioned by Hassan (2006). Firmness changes showed significant $(\mathrm{P}<0.01)$ dissimilarity due to the effect of different postharvest treatments. It was observed that the firmness changes occurred at faster rate in control, whereas the rates were slower in those fruits held at thin plastic film. At 11 days after storage, mango reached firmness score of 5.92 in control treatments. The firmness score was significantly less (3.42) in those fruits held at thin plastic film.

The firmness of mango changes due to conversion of starch into sugars. The results of the experiment are supported by the findings of Pesis et al. (2005). They described that creation of an atmosphere with $11 \% \mathrm{CO}_{2}$ and $12 \% \mathrm{O}_{2}$ was the most effective treatment for delaying ripening of bananas. The bananas remained firmer with nice peel color after 1 week at $20^{\circ} \mathrm{C}$, but the humidity inside the bags caused some decay development on the crown cut. Storing bananas in air-evacuated bags for 24 to 48 hours reduced $\mathrm{O}_{2}$ levels (1\%) and increased the production of $\mathrm{CO}_{2}$ up to (30\%) but perforating the bags dramatically reduced the $\mathrm{CO}_{2}$ level to around (9\%) and increased the $\mathrm{O}_{2}$ level (12\%).

In general, the moisture content decreased with the increase in storage time under different postharvest treatments. It was observed that the significant variations were found in moisture content at all the days after storage due to different postharvest treatments. Moisture content in the pulp of mango was the highest (87.38\%) at 3 days after storage (DAS) due control. On the other hand, the lowest moisture content $(84.50 \%)$ was found in those fruit treated with $1: 1$ neem extract. 


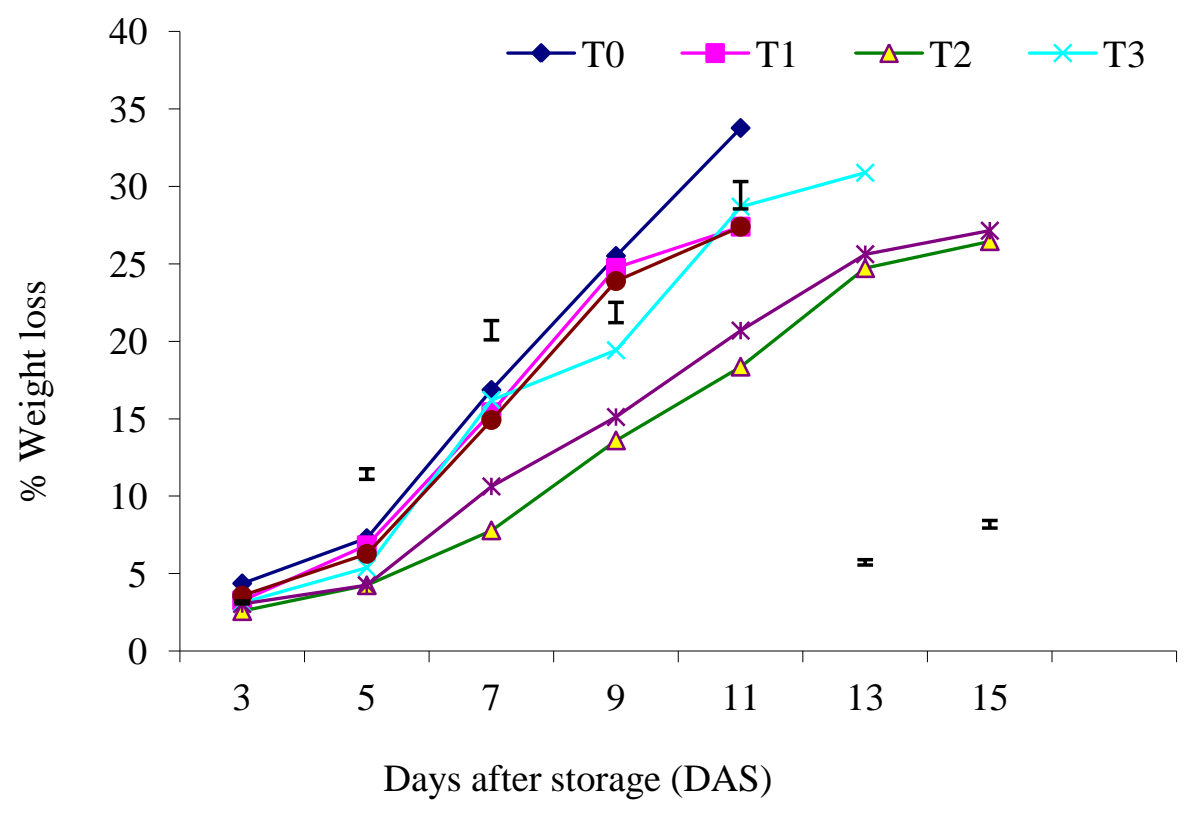

Figure 1. Effect of different postharvest treatments on weight loss at different days after storage. At each day the vertical bars represent LSD at the 5\% level of probability

$\mathrm{T}_{0}$ : Control; $\mathrm{T}_{1}$ : Hot water treatment; $\mathrm{T}_{2}$ : Thin plastic film; $\mathrm{T}_{3}$ : Chlorinated water, $\mathrm{T}_{4}$ : Neem extract; $\mathrm{T}_{5}$ : Garlic extract; * significant at the $5 \%$ level; $* *$ significant at the $1 \%$ level; NS: non-significant; ND: Statistical analysis not done.

Dry matter content varied significantly $(\mathrm{P}<0.01)$ due to the effect of different postharvest treatments. It was observed that the percent dry matter content increased with the increase in storage duration. At the 15 days after storage, neem extract treatment showed the highest $(26.00 \%)$ dry matter content. Similar results were reported by Alam (1990). At the same days after storage, the significantly lowest $(21.40 \%)$ dry matter was recorded in Control.

Highly significant effects, on percent weight loss of mango fruit were observed due to the application of different postharvest treatments. Significantly, the maximum $(30.77 \%)$ weight loss occurred in control at 11 days after storage. By contrast, minimum weight loss $(18.36 \%)$ at 11 DAS was observed in fruits held at thin plastic film. Significantly, the minimum $(2.58 \%)$ weight loss was recorded at initial day after storage also in the fruits held at thin plastic film. The use of neem extract and Garlic extract also contributed to the reduced rate of weight loss (Figure 1).

These results are in agreement with those of Carrillo et al. (2000) who observed that coated or uncoated haden mango in Mexico had an increasing trend of weight loss 
with the passage of storage time. However, weight loss was lower in coated fruit (4.0 to $6.5 \%)$ as compared to control having higher percent weight loss (0.00 to $9.0 \%)$.

These results are further in line with Doreyappa-Gowda and Huddar (2001) who observed that mature green Alphanso and other 7 varieties of mango fruit were influenced by size of fruit, storage temperature, variety and the reduction in length and thickness of fruit during ripening process were attributed to shriveling of fruits due to higher percent loss of water $(12.8 \%)$ from fruits when stored at high temperature $\left(18-34^{\circ} \mathrm{C}\right)$. Perez et al. (2004) also observed that weight loss in Avocado fruit was linear with the storage temperature

Haque (1985) also reported the similar results. He reported that the weight loss of bananas occurred due to the loss of water from the fruits, microbial decay and storage environment like temperature and humidity. High temperature enhanced weight loss but low temperature reduced weight loss during ripening and storage.

Postharvest treatments had highly significant effect on total soluble solids contents of mango. The TSS of mango fruits packaged in control condition ranged from 25.00$30.00 \%$ with a mean value of $27.50 \%$. The increasing trend of percent total soluble solids contents of fruit during storage could be attributed mainly to the breakdown of starch into simple sugars during ripening along with a proportional increase in TSS and further hydrolysis decreased the TSS during storage.

The maximum percent total soluble solid contents of mango were observed in control $(30.00 \%)$ followed by hot water + thin plastic film $(28.50 \%)>$ neem extract $(27.60 \%)$ $>$ garlic extract $(27.30 \%)>$ hot water treatment $(27.00 \%)$ at 12 days after storage. It was observed that the total soluble solids contents increased from 18.00 to $28.50 \%$ up to12 days after storage. The TSS changes were minimal in fruits held at thin plastic film. Garlic extract also exhibited low TSS.

This increase in TSS is due to the conversion of complex carbohydrates into simple sugars. This is correlated with hydrolytic changes in starch and conversion of starch to sugar being an important index of ripening process in mango and other climacteric fruits and further hydrolysis decreased the TSS during storage (Kays, 1991; Kittur et al., 2001). Similar pattern of TSS was observed in green mature Alphanso and other 7 hybrids or varieties of mango fruit that undergone a series of physico-chemical changes and the major changes were increase in TSS content from 8.55 to $19.0 \%$ Brix during ripening and storage at $18-34^{\circ} \mathrm{C}$ (Doreyappa-Gowda and Huddar, 2001). Similar views were expressed by Manzano et al. (1997) who observed that temperature of storage also affect TSS contents, and TSS contents were high $(14.15 \%)$ at high temperature $\left(25^{\circ} \mathrm{C}\right)$ as compared to lower TSS contents $(16.6 \%)$ at low temperature $\left(12^{\circ} \mathrm{C}\right)$ during 20 days of storage experiment.

It was observed that disease incidence was the highest (100\%) in all fruits except in those held at thin plastic film up to 15 days after storage. Generally, the levels of disease incidence were found to gradually increase as the duration of storage 
progressed. The disease levels were maintained lower in those fruit held at thin plastic film, and those treated with neem extract, especially at the early part of storage. This result of less disease is possible due to the delayed pathogenic growth and development in fruits held at perforated low-density polyethylene bag. Similar results were reported by Perez et al. (2002).

The levels of disease severity were significantly influenced by postharvest treatments at the different storage time. It was observed that disease severity status of mango was recorded at 3 days interval from day 1 up to 15 days. At day 15, all fruits were spoiled. Disease severity level trended to increase with duration of storage. The lowest disease severity level $(0 \%)$ was found in mango held in thin plastic film. Disease severity levels were higher especially at the later part of storage in those fruits kept in control. Garlic extracts showed good results in relation to the lower level of disease severity. These results would be attributed to the suppression of fungal growth due to the antifungal properties of garlic. Similar results were reported by Amin (2006).

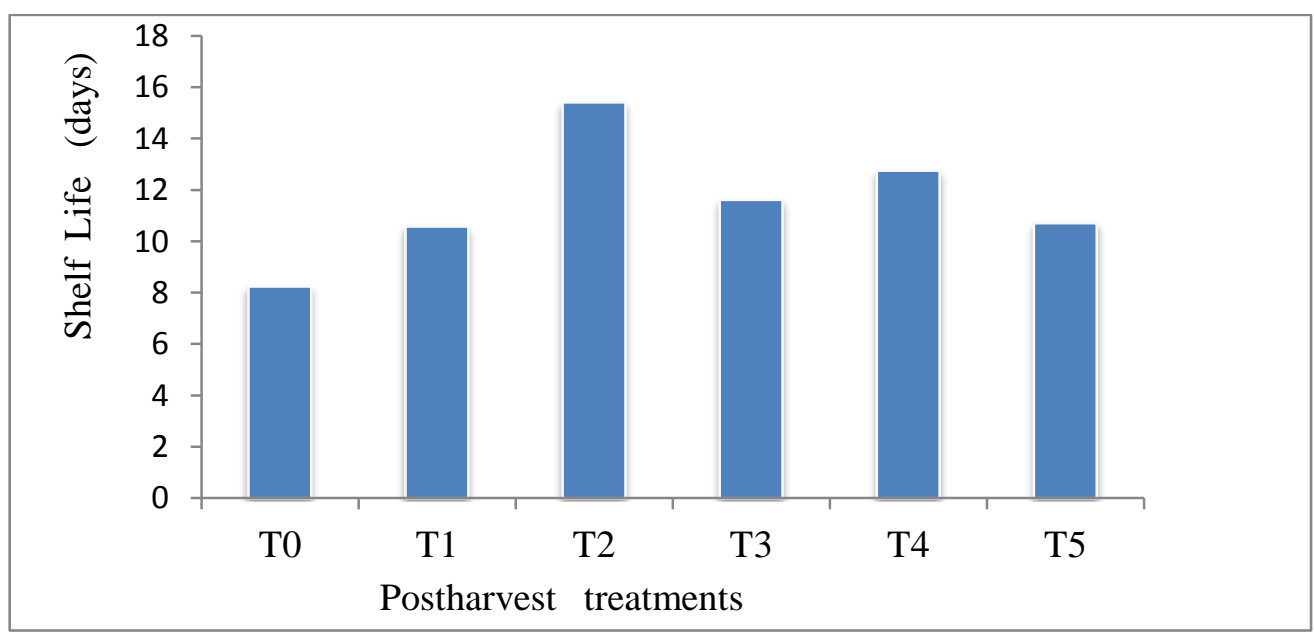

Figure 2. Effect of different postharvest treatments on shelf life at different days after storage

$\mathrm{T}_{0}$ : Control; $\mathrm{T}_{1}:$ Hot water treatment; $\mathrm{T}_{2}$ : Thin plastic film; $\mathrm{T}_{3}:$ Chlorinated water, $\mathrm{T}_{4}$ : Neem extract; $\mathrm{T}_{5}$ : Garlic extract; $*$ significant at the $5 \%$ level; ** significant at the $1 \%$ level; NS: non-significant; ND: Statistical analysis not done.

Shelf life of mango fruits was significantly affected by different postharvest treatments. It was observed that the extension of shelf life of fruits has been one of the most important concerns of the researchers. Results revealed that the longest shelf life (15.41 days) of mango fruits was recorded in those fruit held at thin plastic Film. The shortest shelf life of 8.25 days was observed from the control fruits (Figure 2). 
The longest shelf life as obtained for thin plastic film storage was possibly due to the reduced rate of physico-chemical changes, reduced weight loss and minimal disease severity. Thin plastic film Alphonso mango fruits increased the shelf life of the mango. Pre-cooling has been found to reduce the occurrence and intensity of spongy tissue (Anonymous, 1990).

In the present study, significant extension of shelf life was also recorded in fruit treated neem extract (12.75 days) and garlic extract (10.72 days) (Figure 2). Shelf life extension due to the treatment with garlic extract was possibly due to the suppression of microbial growth. On the other hand, the effects of thin plastic film in shelf life extending would be due to the elevation of $\mathrm{CO}_{2}$ and reduction of $\mathrm{O}_{2}$ inside the bags.

\section{CONCLUSION}

Postharvest treatments had significant effects on color, firmness, total weight loss, moisture content, total soluble solids (TSS), dry matter content, disease severity, disease incidence and shelf life of mango. The best visual appearance was observed the fruits subjected to thin plastic film. Mango remained fresh until day 15 if held in thin plastic film. Although neem extract showed better result in storage until the $12^{\text {th }}$ day of storage. At the $15^{\text {th }}$ day of storage, mango stored at thin plastic film had firmness score less than other treatments. Mango stored in thin plastic film had reduced weight loss until the $15^{\text {th }}$ day of storage. The highest moisture content was recorded in treatment control $(87.38 \%)$ at 3 DAS. The neem extract treatment gained the highest dry matter (26\%). The longest shelf life of 15.41 days was found in fruits kept in thin plastic film. The fruits subjected to control had the showed shortest shelf life (8.25 days).

\section{REFERENCES}

Alam, M.M. (1990). Neem in nematode control. In nematode bio-control (aspect prospects) Delhi, India.CBS. Published distributors Pvt. Ltd, p. 51-55. [Helminth Abst. 46:72].

Amin, A.B.M.R. (2006). Garlic tablet for controlling seed-borne fungal disease of cucumber. An MS thesis submitted of the Department of Plant Pathology, BAU, Mymensingh, p. $1-20$.

Anonymous.(1990). Official Methods of Analysis. Association of Analytical Chemists, $15^{\text {th }}$ ed. Virginia, Arlington, USA. Hot water treatment affects ripening quality storage life of mango. Pakistan Journal of Agricultural Sciences, 44, 23-30.

Anwar, R., and Malik, A.U.(2007). Hot water treatment affects ripening quality and storage life of mango. Pakistan Journal of Agricultural Sciences, 44, 23-30.

Bayarri, S., Calvo, C., Costell, E., and Durán, L. (2001). Influence of color perception of sweetness fruit flavor of fruit drinks. Food Science Technology International, 7(1), 399-404. 
Carrillo, L.A., Ramirez-Bustamante, F., Valdez-Torres, J.B., Rojas-Villegas, R., and Yahia, E.M. (2000). Ripening quality changes in mango fruit as affected by coating with an edible film. Journal of Food Quality, 23, 479-486.

Cole, A.D. (1984). Origin of Cultivated Plants. Vegal Paul Trench Co. London. p. 1-67.

Doreyappy-Gowda, I.N.D., and Huddar, A.G. (2001). Studies on ripening changes in mango (Mangifera indica L.) fruits. Journal of Food Science and Technology, 38, 135-137.

Haque, M.A. (1985). Ripening time weight loss during ripening of "Amritasagar" banana. Bangladesh Journal of Agricultural Research, 10(2), 156-158.

Hassan, M.K. (2006). Constitutive alkenyl resorcinol's and resistance to postharvest diseases in Mango. Ph.D. Thesis, school of agronomy and horticulture, The University of Quensland Australia, p. 286.

Kays, S.J. (1991). Postharvest physiology of perishable plant products. Vas Nostr Rein Hold Book, AVI Publishing Co, p. 149-316.

Kittur, F.S., Saroja, N., Habibunnisa, M., and Tharanathan, R.N. (2001). Polysaccharidebased composite coating formulations for shelf-life extension of fresh banana mango. European Food Research Technology, 213, 306-311.

Manzano, J.E., Perez, Y., and Rojas, E.(1997). Coating waxes on Haden Mango fruits (Mangifera indica L) variety for export. Acta Horticulturae, 455, 738-746.

Mitra, S.K., and Baldwin, E.A.(1997).Postharvest physiology storage of tropical subtropical fruits, CABI International, New York, NY, p. 85-122.0rganization, Australia. p. 1-28

Perez, M.B., Rojas, C., and Del-Rio, M.A.(2002). Effect of lipid type amount of edible hydroxyl propyl methylecellulose lipid composite coatings used to protect postharvest quality of marins cv. Forture. Journal of Food Science, 67(8), 2903-2910.

Pesis, E., Faure, M., and Marinansky-Ben Arie, R. (1997). Induction of chilling tolerance in mango by temperature conditioning, heat, low $\mathrm{O} 2$ ethanol vapours. Acta Horticulturae, $455,629-634$.

Robinson, J.C. (1996). A field comparison of ten Cavendish Sub group banana cultivars selected (Musa AAA) over four crop cycles in the subtropics. Journal of Horticultural Scienc, 68(4), 511-521.

Rodov, V., Fishman, S., Asuncion, R.D., Peretz, J., and Yehoshua, S.B. (1997). Modified atmosphere packaging (MAP) of Tommy Atkins mango in perforated film. Acta Horticulturae, 455, 654-661.

Tharanathan, R.N., Yashoda, H.M., and Prabha, T.N. (2006). Mango (Mangifera indica L.) The King of Fruits-An Overview. Food Reviews International, 22, 95-123. 